\title{
Reading Material Based Gender and Cultural Familiarity and Its Implementation
}

\author{
Elis Susanti , Rini Susilowati, \& Asep Hardiyanto \\ STKIP Muhammadiyah Kotabumi \\ (weasley.ndha@yahoo.com)
}

\begin{abstract}
The schemata theory in reading explains that in the process of comprehending a reading material, a pre-exsistent knowledge of the readers will be active when they read a piece of reading material in which it presents a familiar vocabulary, patterns, or contexts in which they fit into the readers' pre-exsistent knowledge. As a result, readers can recognize what they read because it fits into patterns what they already known. This research was categorized as a type of research and development in which it developed a reading material on the basis of the readers' interest and content familiarity which was constructed under the concept of schemata theory in reading. The research stages consisted of conducting praresearch, developing a prototype, validating the prototype, and applying the design to the research sample. The researchers took a class of $\mathrm{X}$ social science class in SMAN 1 Abung Semuli consisting of 32 students as the research sample to apply the prototype of this research development product. The data analysis shows that the use of reading material based gender and cultural familiarity gives significant influence on the students' reading comprehension in which to the conclusion that the prototype of this research product is effective to be used as a reading material in a reading class.
\end{abstract}

Keywords: Reading comprehension, gender, cultural familiarity, schemata theory.

Comprehension is the main objective of a reading activity in which the process involves many reading aspects. Likewise, Wendling et al, (2007, p.4) stated that comprehension belongs to one of the areas of reading. Comprehension is the process of constructing meaning by coordinating a number of complex process that include word reading, word and world knowledge, and also fluency (Klingner et al, 2007, p.2). In line with Klingner et al, Mikulecky and Jeffries (2007, p.74), define comprehension as an effort to make sense of what is being read and connect the ideas in the text to what the reader already knows. In other words, they state that "comprehending means thinking while reading". In this case, it can be seen that in the process of comprehending a reading material, there will always a process in which the reader recalls their pre-exsistent knowledge or prior knowledge to help them understand what is being read. This is as stated by Cook in Shahmohammadi (2011, p.11) that comprehending a reading material not only involving the reader with the language constructed the text, but also involving the reader with their pre-existent knowledge of the 
world they bring into which is usually called as schema or plural schemata. In the process of reading, the reader's brain will organize the information they read into related schemata (Shahmohammadi, 2011, p.11).

Furthermore, comprehending a reading material will be affected by many aspects that play important role to the students' comprehension success. The two of them are the reader and the reading material or the text variable (Keshavarz \& Ashtarian, 2008, p.98). From the aspect of the reader, gender belongs to one of the aspects from the reader that should get more attention in reading. It is because the fact shows that male and female students have different interest in a reading material. Male tend to like a masculine topic, while female like feminim topic better. This is why several previous researches resulted that male will perform better in reading when they read a masculine topic and vice versa.

Meanwhile, in the aspect of the text variable, several things like text genre, topic familiarity, text structure, text readibility, and others become the factors affecting students' comprehension (Salehi, Lari, \& Rezanejad, 2014, p.266; Mc Namara, 2007, p.41). One of them which is important is the text familiarity in which it refers to how familiar the content, vocabulary, pattern, or the context presented on the text to the readers. In the process of reading comprehension, the text familiarity will deal with the students' pre-exsistent knowledge or what is being called as "schema" or "schemata". Cohen et al. in Salehi, Lari, \& Rezanejad (2014, p.266) defined schema as a stored information in ones' memory that represent general knowledge about objects, situations, events or actions. Meanwhile, according to Rumelhart in Landry (2002) schemata is the "building blocks of cognition" that are used in the process of understanding sensory data, in repossessing information from memory, in organizing aims and sub-goals, in allocating resources, and in leading the flow of the processing system.
In this case, pre-exsistent knowlede or schemata will help the readers to recognize what they read easier because it is a familiar pattern for them. In other words, familiarity with the content of the text dealing with the language, the vocabulary, the certain objects, and so on which close with the readers' culture may help activate the readers' preexsistent knowledge. As a result, students will be able to process what is read even if they have low language ability because their ability to relate what is read to their preexsistent knowledge can compensate for it (Smith in Yusoff, 2004,p.7). Referring to the previous explanation, pre-exsistent knowledge or students' schemata can be activated when the readers read a familiar content in a reading material. Meanwhile, "since male and female students have different emotion, needs, desire and knowledge they have different schemata. Thus, a male-oriented text which becomes the favorite of the male will activate the male's schemata more than a female which then lead to a better comprehension in reading, and vice versa" (Shahmohammadi, 2011,p.12). Thus, it is important that English teachers present a selective reading material which fits to the readers' need. In short, it is essential that the reading material should consider the male and female students' interest as well as present a culturally familiar text which then can help the students comprehend the reading material easier.

In a fact, most of reading materials used by the teacher haven't met the criteria for a reading material which is constructed under the gender-balanced principles and there are also few texts applied are chosen with consideration of their familiarity for the students. An unbalanced material in gender will cause the lack of students' interest to learn the texts. Furthermore, it will cause such discrimination toward the male and female's ability perception in a learning process. As it is reported by the United Nations Fourth World Conference on Women in Guidelines for Mainstreaming Gender in Literacy 
Materials (2010,p.7) that a genderbiased in education which presents the male and female roles traditionally is one of the factors that contributes to the persistence of discrimination against women and gender inequality in many societies. In genderbiased teaching-learning materials, men are usually depicted as stronger person than women. Beside that, man is also usually depicted as being intelligent, skilful, brave, and determined, women are portrayed as being subservient, passive, and dependent. This type of stereotypical depiction could hamper the female students to develop themselves. It can also decrease their interest in learning. Therefore, it is suggested that All gender stereotyping in education should be eliminated. Educational material should reflect a balanced view of the world; in which both woman and men are depicted as those who have the same right, the same ability in doing lifetask, as well as both deserve to a good and brilliant job in life. A balanced depiction of both genders in textual materials and teaching and learning aids is vital in changing the customs, attitudes, and practices towards women and men, on all social and political levels. It also helps to empower women by ensuring that they do not see themselves as being subordinate to men and by encouraging them to challenge unfair discrimination they may experience in society.

In constructing a gender-balanced material in reading, there are several principles to be considered in regard with Guidelines for Mainstreaming Gender in Literacy Materials (2010:10): a) Understand the concept of gender and related concept, b) Undertake an analysis on the exsisting materials in order to eliminate the genderbiased stereotype contained within those materials. In this case, several points need to examine such as: the social reference like status, income and so forth, the activity or action undertaken by both women and men, the social and emotional behaviour of male and female characters includes strengths versus weaknesses, independence versus dependence, and so on, c) Ensure that the teaching and learning material constructed is relevant with the context, d) The materials constructed should be able to empower both gender, e) In order to construct an effective and relevant material with both female and male students, it is essential to seek feedback from the students as well as from the teacher, $\mathrm{f}$ ) Ensure the language used. In this part, several points needed to take into account: Use gender neutral vocabulary such as using chairperson or schoolmamster instead of chairman, replace the use of stewardess by flight attendant, and so on; Avoid certain expression which refers to certain quality of gender like "the right man on the right place", etc; use gender neutral pronoun like they instead of she or he; use the same adjective in describing the equal characteristics; and others.

In line with the previous principles, Commonwealth of Learning (1995, p.58) also stated several principles or guidlines in order that a learning material will be most effective and attractive for both male and female students, they are: a) the relevance and function of examples and topics, b) appropriate cultural content, c) thoughtful treatment of sensitive issues, $d$ ) gender-inclusive language, e) inclusive visuals that avoid stereotypes. First, it is important that the examples as well as the topic chosen is relevant with both male and female's interest, so it woud be effective to attract students' interest to learn the material. Second, it is also important that the material contains an appropriate cultural topic which suits the students' culture, so it would be easier to comprehend by the students. Third, whenever the material discuss about a sensitive issue, it is necessary to be explained more in order that the students able to interpret it appropriately. Fourth, the material should avoid the use of certain terms which refer to certain gender such as pronoun he or she because it will reflect a tendency to one of the gender. It is better to use a neutral terms such the word "they" which show that it refers to both gender. Last, beside words, a visual or picture which presents one of visual reflection 
of gender should also be avoided. To sum up, if the reading material applied in a reading class are chosen or constructed by taking into account to these principles, the material would be effectively help both male and female students to read easier and comprehend the material easier.

Therefore, finally, the researcher is then interested in conducting a research development which will develop a reading material based gender and cultural familiarity in order to reveal a reading material which will be effectively used to help the students develop their reading comprehension ability. Next, the reading material will be implemented limitedly throughout a simple experimental research in one of the tenth classes in SMAN 1 Abung Semuli to examine whether or not it influences students' reading comprehension.

\section{Method}

This research belongs to a research and development design. The researchers developed a reading material based gender and students' culture which is familiar with them. The research stages consisted of a pra-research, construction of the reading material, validation of the reading material, revision, and the implementation of the reading material. In the very begining of the research, a pra-research was conducted to collect the information about the reading material that have been apllied at school, and to collect the information about the need of a representative reading material for the students. The pra-research was conducted by conducting an interview with the English teacher, analyzing the exsisting reading material at school, and doing a library research. Having collected the information needed, the researchers started to construct the reading material based gender and cultural familiarity. Next, it was validated by three experts-two are the expert of material and language, and the rest is the expert of learning media. Then, a revision was done on the basis of the comments and suggestions from the three experts. The last, when the revision was finished, the reading material was then applied to the research sample.

The research sample used in the implementation of the research product was the X social science class of SMAN 1 Abung Semuli Lampung Utara consisting of 32 students. In this case, a quasi experimental research with one group pretest-posttest design was applied in order to examine the influence of the research product on the students' reding comprehension.

\section{Results and Discussion}

\section{The Result of Pra-research}

Referring to the analysis of the applied reading material at school, it was found that 4 (four) out of the 8 (eight) units still presented an unbalanced gender based material. For instance, in a balanced gender based material, it is suggested to avoid the use of only one name, or certain pronoun which refers to only a certain prototype either male or female. However, the two reading texts in Unit 1 on page 4 and 5 , it was found that the texts only contains a female name- "Hanah" and "Saidah" which shows an unbalanced gender based material. It will be more representative for both male and female students if the texts contain both male and female gender, so it will be balance.

From the aspect of cultural familiarity, there are only 3 (three) units found contained a native culture of the students. Meanwhile, the other units even contained international culture which are unfamiliar for the students.

\section{The Result of Reading Material Development}

The research product resulted a reading material consisting of 8 (eight) units as follows:

Unit 1 : Expressing Introduction

Unit 2 : Congratulating \& Complimenting Unit 3 : Future Plan 
Unit 4 : Descriptive Text

Unit 5 : Announcement Text

Unit 6 : Simple Past Tense \& Present Perfect Tense

Unit 7 : Recount Text

Unit 8 : Narrative Text

The construction of the reading material was done through the development of the basic competence including in the school curriculum especially for the tenth grade students of SMA. Each of the units presented reading texts in which they were constructed by considerations of a balanced material for both male and female students so that they will be interesting for both of them. Every unit consisted of reading material containing gender-neutral vocabulary, color, picture, and other aspects presented which were chosen on the basis of gender-balanced principles. Likewise, the materials also contain series of activities showing the same capability of

\section{COMPREHENSION}

\section{Read the following text carefully, then answer the} comprehension questions!

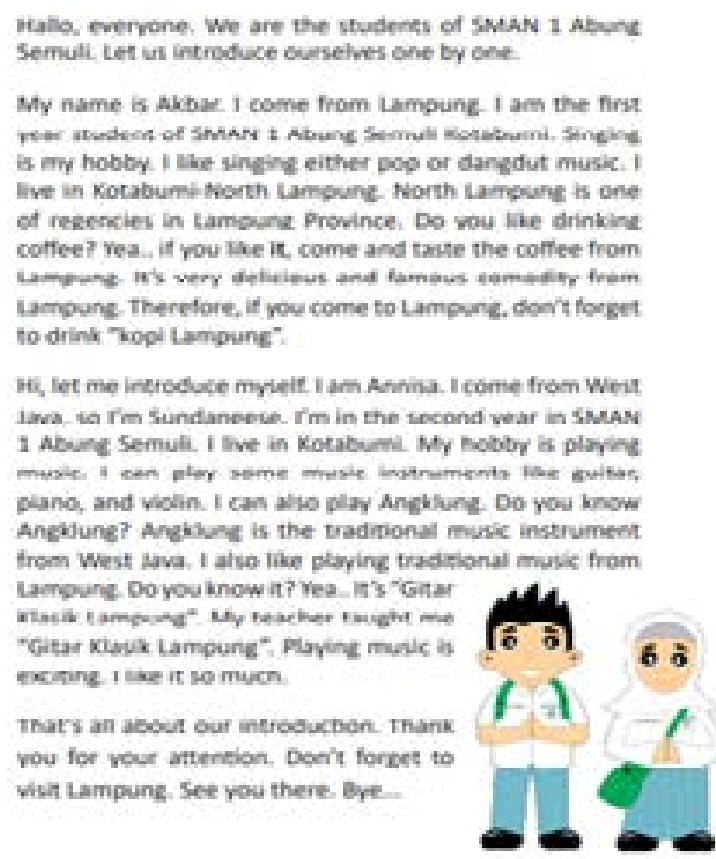

Figure 1. Reading Material Based Gender and Cultural Familiarity Example both male and female students indicating that both gender are equal in deserving a success in the same context. Beside focus on the gender-balanced principles, every unit of the reading material is also constructed under the principle of cultural familiarity of the students' local culture which is nationally admitted and familiar. Figure 1 shows the example of how the reading material constructed.

The picture is one of reading material constructed about introduction. It presents a picture of both male and female students in which they are introducing themselves to their friends. The use of both gender in picture is one of the gender-balanced principles in constrcting a gender-neutral material in literacy as well as it will attract the interest of both male and female students. Likewise, the personal information about the students' hobby in which the male-student (Akbar) is depicted to have a singing as his hobby, while the female-student (Annisa) has playing music are an example of the gender-balanced principle in which both gender are depicted to have equal ability. In reard with the cultural familiarity concept, the material contains such terms, information, and context in relation with Lampung and Sundanese culture which is quite familiar with the students.

\section{The Result of Experts Validation}

The first validation was conducted by two experts of reading material-Miss Rulik Setiani, S.S.,M.Pd., and Miss Dewi Sri Kuning, S.Pd.,M.Pd. the complete result is presented as follows.

From the aspect of content appropriateness, it was found the total score of 61 in which it belongs to "very good". Meanwhile, score of 70 was obtained for the aspect of the material presentation appropriatness which belongs to "very good" also. Last, from the aspect of evaluation, the constructed reading material obtained the score of 18 which belongs to "good". To sum up, from the score of each aspect it was found that the constructed reading material has met the 
Table 1. Interval Score of Pretest

\begin{tabular}{lrrr}
\hline No & $\begin{array}{c}\text { Interval } \\
\text { Class }\end{array}$ & Frequency & $\begin{array}{c}\text { Percentage } \\
(\%)\end{array}$ \\
\hline 1 & $10-20$ & 3 & 9,375 \\
2 & $21-31$ & 5 & 15,625 \\
3 & $32-42$ & 2 & 6,25 \\
4 & $43-53$ & 7 & 21,875 \\
5 & $54-64$ & 6 & 18,75 \\
6 & $65-75$ & 9 & 28,125 \\
\hline Total & & 32 & 100 \\
\hline
\end{tabular}

Table 2. Interval Score of Posttest

\begin{tabular}{lrrr}
\hline No & $\begin{array}{c}\text { Interval } \\
\text { Class }\end{array}$ & Frequency & \multicolumn{1}{c}{$\begin{array}{c}\text { Percentage } \\
(\%)\end{array}$} \\
\hline 1 & $15--27$ & 1 & 3,125 \\
2 & $28--40$ & 4 & 12,5 \\
3 & $41--53$ & 4 & 12,5 \\
4 & $54--66$ & 11 & 34,375 \\
5 & $67--79$ & 7 & 21,875 \\
6 & $80--92$ & 5 & 15,625 \\
\hline Total & & 32 & 100 \\
\hline
\end{tabular}

Table 3. Descriptive Statistics of the Pretest

\begin{tabular}{|c|c|c|c|}
\hline & & Pretest & Posttest \\
\hline \multirow[t]{2}{*}{$\mathrm{N}$} & Valid & 32 & 32 \\
\hline & Missing & 0 & 0 \\
\hline \multicolumn{2}{|c|}{ Mean } & 48,91 & 60,78 \\
\hline \multicolumn{2}{|c|}{ Median } & 50,00 & 60,00 \\
\hline \multicolumn{2}{|c|}{ Mode } & 45 & 60 \\
\hline \multicolumn{2}{|c|}{ Std. Deviation } & 18,216 & 17,418 \\
\hline \multicolumn{2}{|c|}{ Variance } & 331,830 & 303,402 \\
\hline \multicolumn{2}{|c|}{ Skewness } &,- 363 &,- 447 \\
\hline \multicolumn{2}{|c|}{$\begin{array}{l}\text { Std. Error of } \\
\text { Skewness }\end{array}$} & ,414 & ,414 \\
\hline \multicolumn{2}{|c|}{ Range } & 65 & 75 \\
\hline \multicolumn{2}{|c|}{ Minimum } & 10 & 15 \\
\hline \multicolumn{2}{|c|}{ Maximum } & 75 & 90 \\
\hline \multicolumn{2}{|c|}{ Sum } & 1565 & 1945 \\
\hline
\end{tabular}

appropriateness criteria to be implemented as a reading material at school. However, both of the experts agreed that the constructed reading material still needs revision. Some suggestions and critisms were given to the further revision of the constructed reading material.

Next, the second validation conducted by the expert of learning media revealed a result that from the two aspects measuredthe chart appropriateness and the language appropriateness, both of those aspects met a "very good" criteria which means that the constructed reading material has met the appropriateness standard to be implemented as a reading material at school.

\section{The Result of Product Implementation} throughout A Simple Experimental Research

Having conducted an experimental research for the product implementation, the data of the pretest and posttest obtained is presented in Table 1 and Table 2, respectively. Furthermore, the descriptive statistics of the pretest is presented in Table 3.

Refering to the description, it is known that the mean score of the students increases in the posttest in which in pretest it is 48,91 , then after the implementation of the prototype it increases to 60,78 . Beside that, the increase is also for the minimum and maximum score before and after the implementation of the prototype in which the minimum score increases from 10 to 15 , and the maximum score increases from 75 to 90 . This findings shows that the implementation of the prototype in this class has significantly increased the students' score in reading comprehension. However, in order to test the effectiveness of the prototype toward the students' reading comprehension, a statistical measurement was done using t-test analysis of parametric statistics.

Before the data was analyzed using parametric statistical analysis, it was firstly analyzed to test the normality and homogeneity of the data. The result of normality test can be seen in Table 4.

The result shows that the value of significant of both data $(0,146$ and 0,200$)$ were greater than the value of $\alpha(0,05)$, so it was found that both of the data were normally 
distributed.

Table 4. Normality Test Result

\begin{tabular}{|c|c|c|c|c|c|c|}
\hline & \multicolumn{2}{|c|}{$\begin{array}{l}\text { Kolmogor- } \\
\text { ov-Smirnov }^{\text {a }}\end{array}$} & \multicolumn{4}{|c|}{ Shapiro-Wilk } \\
\hline & $\begin{array}{l}\text { Sta- } \\
\text { tistic }\end{array}$ & Df & Sig. & $\begin{array}{l}\text { Sta- } \\
\text { tistic }\end{array}$ & & Sig. \\
\hline $\begin{array}{l}\text { Pre- } \\
\text { test }\end{array}$ & ,135 & 32 & , 146 & ,950 & 32 & , 141 \\
\hline $\begin{array}{l}\text { Post- } \\
\text { est }\end{array}$ & 112 & 32 &, $200^{*}$ & 972 & 32 & ,542 \\
\hline \multicolumn{7}{|c|}{$\begin{array}{l}\text { *. This is a lower bound of the true significance. } \\
\text { a. Lilliefors Significance Correction } \\
\text { Table 5. The Result of Homogeneity test }\end{array}$} \\
\hline \multicolumn{2}{|c|}{$\begin{array}{r}\text { Levene } \\
\text { Statistic }\end{array}$} & \multicolumn{2}{|c|}{ df1 } & \multicolumn{2}{|c|}{ df2 } & Sig. \\
\hline \multicolumn{2}{|r|}{,516 } & \multicolumn{2}{|r|}{1} & \multicolumn{2}{|c|}{62} & ,475 \\
\hline
\end{tabular}

Next, the result of homogeneity test is presented Table 5. It was found that the value of significant $(0,475)$ is also greater than the value of $\alpha(0,05)$, so the data is homogeneous. Having found that both of the data were normally distributed and homogeneous, it was then analyzed using independent t-test to find out the influence of the constructed reading material toward the students' reading comprehension. The result of $\mathrm{t}$-test analysis is presented in Table 6.

It was found that the value of significant $(0,01)$ is less than the value of $\alpha(0,05)$, so H0 is rejected and $\mathrm{Ha}$ is accepted. In conclusion, there is signifcant influence of reading material based gender and cultural familiarity toward the students'reading comprehension of the $\mathrm{X}$ social science class of SMAN 1 Abung Semuli.
In other words, it shows that the reading material or the research product is effective to be implemented to improve students' reading comprehension. This research finding is relevant with the previous researche conducted by Brantmeier (2003) which resulted that the male students performed better comprehension in a text about "boxing" which is male-oriented text rather than a text about "household" which is female-oriented text. In accordance with that research finding, it is assumed that a gender-oriented text in reading material will determine the students' interest which then lead to their reading comprehension performance. It is found that the male-students perform better in reading a text which refers to their gender rather than reading a femaleoriented text. Likewise, the gender based material applied to the students of the tenth grade in SMAN 1 Abung Semuli can attract the students' interest because it was constructed under the gender-balanced principles in which the use of vocabulary, certain terms, activity undertaken by such characters, color, picture and other aspects are in consideration of gender-neutral principles. As the result, the reading material is easier to understand and lead to the students' better comprehension.

Additionally, this research result also in line with the previous research about cultural familiarity conducted by Liu (2015, p.74) entitled "The Perception of Cultural Familiarity and Background Knowledge on Reading Comprehension for Intermediate EF Students" which revealed that the students who read a

Table 6. The Result of t-test Analysis

\begin{tabular}{|c|c|c|c|c|c|c|c|c|}
\hline & & \multicolumn{7}{|c|}{ t-test for Equality of Means } \\
\hline & & \multirow[t]{2}{*}{$\mathrm{t}$} & \multirow[t]{2}{*}{ df } & \multirow[t]{2}{*}{$\begin{array}{l}\text { Sig. } \\
\text { (2-tailed) }\end{array}$} & \multirow[t]{2}{*}{$\begin{array}{l}\text { Mean } \\
\text { Differ- } \\
\text { ence }\end{array}$} & \multirow[t]{2}{*}{$\begin{array}{l}\text { Std. Error } \\
\text { Differ- } \\
\text { ence }\end{array}$} & \multicolumn{2}{|c|}{$\begin{array}{l}\text { 95\% Confidence } \\
\text { Interval of the Differ- } \\
\text { ence }\end{array}$} \\
\hline & & & & & & & Lower & Upper \\
\hline \multirow[t]{2}{*}{ Score } & $\begin{array}{l}\text { Equal varianc- } \\
\text { es assumed }\end{array}$ & $-2,665$ & 62 & ,010 & $-11,875$ & 4,455 & $-20,781$ & $-2,969$ \\
\hline & $\begin{array}{l}\text { Equal vari- } \\
\text { ances not } \\
\text { assumed }\end{array}$ & $-2,665$ & 61,876 &, 010 & $-11,875$ & 4,455 & $-20,782$ & $-2,968$ \\
\hline
\end{tabular}


material associated with their native culture are easier to understand what is being read because in regard with the schemata theory that human brain will organize such information they read with the plural schemata or prior knowledge exsisting within their memory. In this case, reading a culturally familiar text activate their prior knowledge and help them understand the material easier which then lead them to have better comprehension.

\section{Conclusion}

In regard with the research result, the reading material based gender and cutural familiarity constructed from this research is effective to be implemented in order to improve students' reading comprehension meaning that a balanced-gender principles applied in the construction of the reading material proves to be able to increase the students' interest either male or female student. Additionally, culturally familiar content, vocabulary, context, place, and other aspects contained in the reading material help the students activate their pre-exsistent knowledge during the reading comprehension process which then finally eased them to comprehend what is being read.

\section{Acknowledgement}

This research is funded by Direktorat Riset dan Pengabdian Masyarakat Direktorat Jendral Penguatan dan Pengembangan Kementrian Riset, Teknologi, dan Pendidikan Tinggi sesuai dengan Kontrak Penelitian Tahun Anggaran 2018.

\section{References}

Brantmeier, C. (2003). Does gender make a difference? Passage content and comprehension in second language reading. Reading in a Foreign Language, 15 (1), 10-27.

Keshavarz, M. H., \& Ashtarian, S. (2008).
The relationship between Iranian EFL learners'gender and reading comprehension of three different types of text. IJAL, 11(1), 97-113.

Klingner, Janet K. (2007). Teaching Reading Comprehension to Students with Learning Difficulties. New York: The Guilford Press.

Landry, K. (2002). Schemata in second language reading. The Reading Matrix, 2(3).

Liu, Yi-Chun., (2015). The Perception of Cultural Familiarity and Background Knowledge on Reading Comprehension for Intermediate EFL Students. International Journal of Language and Literature, 3 (1), 71-75.

Mikulecky, Beatrice S. and Jeffries, Linda. (2007). Advanced Reading Power. United States of America: Pearson-Longman.

Salehi, Mohammad., Lari, Zahra., \& Rezanejad, Atefeh. (2014). The Effects of Gender and Genre on Language Learners' Reading Comprehension Ability. Education Journal. 3(5), 266-271.

Shahmohammadi, Nayereh. (2011). The Effect of Gender Base Materials on Reading Comprehension. International Journal of Human Resource. 1(2). 